\title{
Dignidade Da Natureza: Uma Ressignificação Da Dignidade Humana
}

\author{
Ingrid de Lima Barbosa * \\ Universidade Federal do Rio Grande do Norte, Programa de Pós-Graduação em Direito, Natal-RN, \\ Brasil. \\ iD https://orcid.org/oooo-0002-1589-5228 \\ José Orlando Ribeiro Rosário * \\ Universidade Federal do Rio Grande do Norte, Programa de Pós-Graduação em Direito, Natal-RN, \\ Brasil.
}

Resumo: Atualmente, proclama-se a era da conscientização animal, isto é, a superação do paradigma antropocêntrico que coloca o ser humano acima de qualquer espécie. Tal mudança de perspectiva se inicia com a ressignificação da dignidade humana para além dos animais humanos, atribuindo-lhe uma vertente ecológica. Pretende-se, portanto, analisar a possibilidade de abertura linguística da dignidade humana para o viés ecológico da atualidade e, assim, propugnar pela dignidade da vida, que vai além da espécie humana. Utilizou-se do método dialético, com o objetivo de apresentar uma nova concepção da realidade, aliado à abordagem teórica-analítica e documental, de cunho qualitativo, com a análise crítica das interpretações atribuídas ao princípio da dignidade humana, bem como da mudança da realidade que hoje se apresenta aos estudiosos, com a maior preocupação conferida ao meio ambiente como um fim em si mesmo. Concretizou-se tal método científico com o uso de livros, artigos científicos, trabalhos acadêmicos (Dissertações), decisão de tribunal superior e documentos internacionais. Concluiuse que a leitura constitucional e internacional da dignidade humana deve acompanhar as novas percepções que despontam com o desenvolvimento do estudo do meio ambiente e de seus componentes, sem descurar da possibilidade de que os animais não-humanos possam titularizar direitos perante os homens.

Palavras-chave: Animais. Dignidade Humana. Senciência.

* Mestranda em Constituição e Garantias de Direitos pela Universidade Federal do Estado do Rio Grande do Norte - UFRN. E-mail: ideelima@hotmail.com

\footnotetext{
** Doutor em Direito pela Faculdade Autônoma de Direito de São Paulo - FADISP. Professor Associado da Universidade Federal do Rio Grande do Norte. Docente permanente no Programa de Pós-graduação em Direito, curso de Mestrado em Direito e Programa de Pós-graduação em Gestão de Processos
} Institucionais, Mestrado Profissional, da UFRN. E-mail: orlandoogribeiro@gmail.com

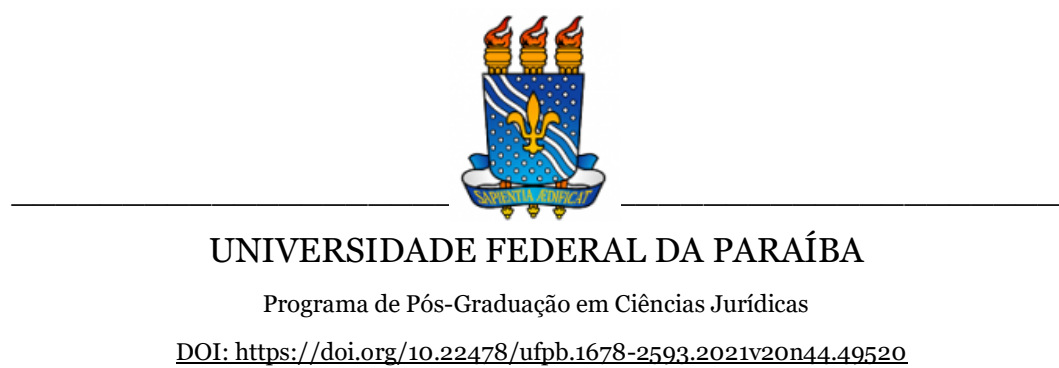




\title{
Dignidade Da Natureza: Uma Ressignificação Da Dignidade Humana
}

\author{
Ingrid de Lima Barbosa
}

José Orlando Ribeiro Rosário

\section{INTRODUÇÃO}

Nos dias atuais, está-se vivenciando uma mudança paradigmática, com a era da conscientização animal, o que implica diretamente na conformação dos valores que circundavam a sociedade global, levando a novos contornos sobre quem somos (animais humanos) e em qual lugar nos encaixamos.

Tais reflexões apontam as incertezas e as incongruências em torno de uma concepção fechada e perfeita sobre a dignidade humana, princípio fundador de uma percepção comunitária sobre a qualidade de vida, o bem-estar e a forma de relação dos seres humanos. Embora as afirmações kantianas sobre a superação da minimização do homem, e sua colocação como ser pensante e condutor das mudanças, o homem, criatura, não está sozinho no globo terrestre.

E é a partir dessa constatação que se torna problemático pensar a atribuição de dignidade somente aos humanos, quando se está cercado de inúmeras espécies animais, cujas manifestações existenciais se assemelham em muito a dos seres racionais, e quando o paradigma especista e antropocêntrico foi o agente motor de diversas situações degradantes da saúde planetária.

A dignidade, não sendo um conceito estanque, perpassa por todos os âmbitos sociais, não atraindo para si somente a ideia abstrata e filosófica de que o homem é um "fim em si mesmo", mas se alimenta 
das mudanças culturais, sociais, políticas, ecológicas, e é, por isso, que um dia mulheres não podiam votar, nem trabalhar, e que negros eram coisas a serem compradas e vendidas, e, hoje, o voto é um direito de todos e os negros são pessoas, com dignidade.

Limitar a possibilidade de enxergar a dignidade a seres da mesma espécie é limitar um conceito que é poroso, dinâmico e transformador, capaz de absorver as novas perspectivas ecológicas, particularmente iniciadas após a Segunda Guerra Mundial, como a proclamação da proteção do meio ambiente contra atos destruidores e da salvaguarda dos animais contra atos cruéis, mesmo que, até então, a crueldade fosse um qualidade-ato somente entendível entre humanos.

Portanto, a problemática gira em torno da possibilidade de se ampliar a interpretação da dignidade para incluir todos os seres vivos, inclusive os animais não-humanos, por meio da vertente ecológica.

Diante disso, o presente artigo tem o objetivo de analisar a possibilidade de abertura linguística da dignidade humana para o viés ecológico da atualidade e, assim, propugnar pela dignidade da vida, que vai além da espécie humana para abarcar todos os seres vivos. Para tanto, utilizar-se-á do método dialético, com o objetivo de apresentar uma nova concepção da realidade.

A abordagem metodológica a ser utilizada é a teórica-analítica e documental, de cunho qualitativo, com a análise crítica das interpretações atribuídas ao princípio da dignidade humana, bem como da mudança da realidade que hoje se apresenta aos estudiosos, com a maior preocupação conferida ao meio ambiente como um fim em si mesmo. Por isso, serão usados livros, artigos científicos, notícias veiculadas em sítios da internet, trabalhos acadêmicos (Dissertações), decisão de tribunal superior e documentos internacionais. 
Immanuel Kant foi quem introduziu os aspectos fundamentais da dignidade humana como hoje se concebe. Em seu livro "Fundamentação da metafísica dos costumes", o autor apresenta um verdadeiro postulado de conduta: "Age de tal maneira que uses a humanidade, tanto na tua pessoa como na pessoa de qualquer outro, sempre e simultaneamente como fim e nunca simplesmente como meio" (KANT, 2007, p. 69).

Esse postulado é conhecido como a fórmula do "fim em si mesmo", conforme Daniel Sarmento (2016, p. 106), a qual traz a ideia de valor intrínseco da pessoa, e, portanto, da sua dignidade, pelo simples fato de ser um ser humano. Para Kant (2007, p. 67-68), uma pessoa merece ser respeitada como ser racional e autodeterminante, de modo que em nenhuma hipótese pode ser tratada como objeto.

Com o foco na espécie humana, Kant (2003, p. 284-285) não vislumbrava a possibilidade de se atribuir direitos ou, mesmo, valor, aos animais, de modo que, quanto aos animais não-humanos somente seria possível o status de objeto de direito, na correspondência de um dever indireto para os humanos. De fato, o pensador alemão entendia que os animais somente poderiam ser coisas apropriáveis, uma vez que podiam ser utilizadas, consumidas e mortas. E, assim, na sua análise, "Embora tal argumento a favor desse direito [...] seja válido relativamente a animais, que podem ser propriedade de alguém, simplesmente não pode ser aplicado a seres humanos" (KANT, 2003, p. 188).

Isto é, aos animais humanos não é possível a subjugação por serem racionais, autônomos e, portanto, detentores de valor intrínseco, enquanto os demais animais nada mais são que objetos utilizados em favor dos homens, e assim podem ser submetidos a quaisquer situações de submissão, desde que o não haja subversão da integridade humana. Segundo Kant (2007, p. 68): 
irracionais, apenas um valor relativo como meios e por isso se chamam coisas, ao passo que os seres racionais se chamam pessoas, porque a sua natureza os distingue já como fins em si mesmos, quer dizer como algo que não pode ser empregado como simples meio e que, por conseguinte, limita nessa medida todo o arbítrio.

Assim, a dignidade para Kant tem por base a autonomia, que expressa a vontade livre do ser e a sua habilidade de se autodeterminar, de guiar seus passos, de se definir (KANT, 2007, p. 79). Quando algo está além de qualquer preço, não podendo ser substituído por outro, ele possui valor, ele tem dignidade; as coisas possuem preço, os homens dignidade.

É esse o pressuposto que confere fundamento à dignidade humana, como foi cunhada durante os séculos. Nascida na filosofia, tem como contornos a justiça, a segurança e a solidariedade, sendo, portanto, a justificação dos direitos fundamentais. Posteriormente, ingressando na política, a dignidade passa a fazer parte de documentos internacionais e nacionais, sendo considerada fundamento do Estado Democrático e moldada pelos Poderes Executivo e Legislativo. Por fim, no século XX, ingressa no Direito, adquirindo o status de princípio jurídico $^{1}$ (BARROSO, 2010, p. 10).

E foi essa aproximação ao Direito que a tornou eminentemente principiológica, negando a ruptura entre Direito e Moral. A dignidade humana passou, então, a servir como justificação moral e fundamento normativo para os direitos constitucionais (BARROSO, 2010, p. 11).

Refletindo sobre a concepção de dignidade humana, Jorge Reis Novais (2015, p. 47-48) informa que somente depois de perfilhar caminhos na filosofia e na política foi que a dignidade foi recepcionada pelo Direito Constitucional, tendo sido a Constituição da Finlândia de 1919, a primeira a trazer tal acepção. Em posição contrária, Gilmar

\footnotetext{
${ }^{1}$ Segundo Joaquim Gomes Canotilho (2003, p. 1160-1162), tanto as regras como os princípios são normas, cabendo a sua distinção em razão de serem espécies. Especificamente quanto aos princípios, aduz que são normas que carregam em si a abstração e a indeterminabilidade, sendo, portanto, componentes estruturais do ordenamento jurídico. Os princípios estariam na base das regras, figurando como vetores axiológicos fundamentais.
} 
Ferreira Mendes (2013, p. 85) afirma que a Lei Fundamental da Alemanha de 1949 foi a que estabeleceu a transição da dignidade de valor filosófico para o texto jurídico.

A par da divergência temporal, o fato é que a dignidade somente ingressou no cenário jurídico, como atualmente se concebe (princípio jurídico), após a Segunda Guerra Mundial, mormente com a Carta das Nações Unidas. A partir de então, a dignidade humana se tornou um princípio de qualidade universal, servindo de norte para a comunidade internacional e para as ordens democráticas que se formavam (NOVAIS, 2015, p. 50-51).

Aos poucos, o referido princípio jurídico passou a ganhar variados contornos, sendo aplicado em diversos contextos, perpassando da bioética ${ }^{2}$ à liberdade de expressão, demonstrando a dificuldade de se estabelecer um conceito universal sobre a dignidade humana, tendo em vista haver muitos aspectos que implicam no tratamento do homem como um "fim" (BARROSO, 2010, p. 18).

Em razão disso, tornou-se necessária a conceituação uniforme da dignidade humana a fim conferir concretude a sua aplicação. Barroso (2010, p.19), nesse sentido, realça os três conteúdos essenciais da dignidade humana, quais sejam, o valor intrínseco, a autonomia e o valor social da pessoa humana.

O valor intrínseco está conectado à natureza que é comum a todos os seres humanos. Trata-se, na verdade, da distinção entre o ser humano e os demais seres e coisas. É por esse olhar que a dignidade é inviolável. A autonomia se refere à racionalidade, à capacidade de conceber valores e realizar escolhas, isto é, de autodeterminar-se. Por fim, o valor social implica na relação do ser humano com o grupo, com os valores comunitários; é o que efetivamente limita a autonomia da

2 Área relativamente recente no Brasil, mas que ganhou importância após o fim da ditadura militar, preocupando-se com os aspectos axiológicos e com a sua não restrição aos conflitos clínicos e da pesquisa médica, como nos Estados Unidos da América. Pretendia-se uma bioética com propósitos globais, na luta por condições dignas a todos os seres (CARVALHO, Regina Ribeiro Parizi; MARTINS, Gerson Zafalon; GRECO, Dirceu Bartolomeu, 2017, p. 219). 
vontade, por implicar responsabilidades e deveres (BARROSO, 2010, p. 27-28).

Para Sarmento (2016, p. 70), a concepção da dignidade, conteúdo e limites, depende da análise de cada sistema jurídico, tendo em vista que os exatos contornos do referido princípio podem mudar a depender do tempo e do espaço. No ordenamento jurídico ${ }^{3}$ brasileiro, além de princípio, a dignidade humana é fundamento da República Federativa do Brasil (artigo 1, III, da Constituição Federal), irradiando-se para todos os ramos jurídicos (SARMENTO, 2016, p. 80)4, por exemplo, as premissas são antropológicas, de modo que a dignidade está atrelada à pessoa, como ser racional, sentimental e corporal, autônomo, e que precisa ter garantido o mínimo existencial.

Em termos gerais, o referido autor adota as mesmas premissas básicas de Barroso (2010, p. 21), apontando o valor intrínseco, a autonomia e a sociabilidade dos seres humanos como critérios para a definição da dignidade humana (SARMENTO, 2016, p. 92). De igual forma, Novais (2015, p. 58-59) aponta a ideia de atribuição de um valor próprio ao ser pelo simples fato dele ser humano, assim como a sua independência e garantia do mínimo necessário para sua sobrevivência.

Os aspectos acima delineados apontam para a existência de funções desenvolvidas pela dignidade humana, sendo ela instrumento hermenêutico para guiar os processos de interpretação, assim como critério para a verificação dos interesses preponderantes em caso de conflitos e parâmetro de controle constitucional (SARMENTO, 2016, p. 77).

Todavia, não se trata de um princípio absoluto. Segundo Sarmento (2016, p. 97), assim como Ingo Wolfgang Sarlet (2012, p.110), a dignidade humana não pode ser considerada como um

3 O ordenamento jurídico é, conforme Jonathan Barros Vita (2010, p. 41), o texto da forma como foi legislado, isto é, o dado bruto, enquanto o sistema é o produto da interpretação e sistematização pela Ciência do Direito.

4 O Constituinte brasileiro "reconheceu categoricamente que é o Estado que existe em função da pessoa humana, e não o contrário, já que o ser humano constitui a finalidade precípua, e não meio da atividade estatal" (SARLET, 2012, p. 103). 
princípio absoluto, uma vez que tal assertiva traria incompatibilidades inconciliáveis, mormente quando diante de uma sociedade complexa e o princípio em xeque tratar de tantos aspectos da vida humana-social quantos existem. Ademais, afirmar a relatividade da dignidade humana não retira a sua força como também a natureza absoluta de algumas proibições ou considerações, como a tortura, cuja proibição é absoluta.

Como se observa, a dignidade, assim como entendida em seu papel clássico, é um princípio de variadas facetas, tendo o homem como pressuposto e fim da norma e da conduta. Apesar disso, atualmente, e diante das tentativas de definição precisa do princípio, é possível apontar outros aspectos fora da órbita humana e, até mesmo, extraíveis do valor social da dignidade. Entretanto, antes que se passe a tratá-la é preciso analisar a dignidade no Direito Internacional e no ordenamento jurídico brasileiro.

\section{A DIGNIDADE HUMANA: O DIREITO INTERNACIONAL AOS DIREITOS NACIONAIS}

Consoante já informado no capítulo anterior é a concepção de Immanuel Kant que prevalece nos documentos jurídicos no tocante à dignidade humana, atributo somente encontrado nos humanos, por serem seres racionais.

Todavia, para Sidney Guerra (2009, p. 108), o direito internacional clássico não atribuía ao ser humano a condição de sujeito de direitos, cujo status somente era conferido aos Estados, visto que a comunidade internacional era estritamente interestatal.

De fato, os seres humanos somente passaram a um plano de destaque no direito internacional quando do desenvolvimento do Direito Humanitário, com a Liga das Nações e a Organização Internacional do Trabalho (GUERRA, 2009, p. 109). 
Segundo Christophe Swinarski (2003, p. 36), o Direito Internacional Humanitário apresenta aspecto geral, regendo toda a conduta praticada em situações de conflito armado, objetivando, portanto, restringir os meios de combate e proteger as vítimas.

Percebe-se, portanto, que esses novos institutos e instituições retiraram o olhar somente dos Estados no âmbito internacional, e deitaram considerações sobre os seres humanos, componentes dos entes políticos.

E tal transformação só se consolidou após a Segunda Guerra Mundial, quando os países que lutavam contra o eixo nazista resolveram criar a Organização das Nações Unidas, cuja Carta foi assinada em 1945, e em seu preâmbulo foi consignada a preocupação com os direitos da pessoa. Insta salientar, inclusive, que no âmbito das Nações Unidas, foi criada uma Comissão de Direitos Humanos, inserida no Conselho Econômico e Social (GUERRA, 2009, p. 111).

Efetivamente, consoante Sarlet (2012, p. 99), somente no decorrer do século XX, e fora algumas exceções, após a Segunda Grande Guerra, a dignidade passou a ser reconhecida nas Constituições dos Estados, mormente com a Declaração Universal da ONU.

Em 1948, com a possibilidade de se conferir efetivos direitos aos seres humanos na seara internacional, foi proclamada a Declaração Universal de Direitos Humanos pela Assembleia Geral das Nações Unidas. O Brasil a assinou na mesma data.

Entretanto, segundo Helenara Braga Avancini (2013, p. 80), embora a Declaração tenha seu mérito, o reconhecimento dos direitos humanos internacionais se deu com mais clareza na Carta Internacional de Direitos Humanos, a qual foi sendo construída ao longo do tempo, a partir da junção de inúmeros documentos internacionais.

Além da referida Carta Internacional, portanto, há diversos pactos internacionais que tratam dos direitos humanos, como o Pacto de San José da Costa Rica e a Carta dos Direitos Fundamentais da União Europeia (AVANCINI, 2013, p. 80-81). 
Sobre o Pacto de San Jose da Costa Rica, Eduardo Biacch Gomes e Ayeza Schmidt (2014, p. 138) destacam que no artigo 5.1 é consagrado o direito à integridade pessoal, a qual engloba a moral e as partes física e psíquica, sendo dever dos Estados-Partes a adaptação de seu ordenamento jurídico interno às diretrizes internacionais, possibilitando o exercício pleno dos direitos humanos pelos indivíduos.

O aludido pacto, que foi assinado em 1969, é um dos fundamentos da proteção internacional aos direitos humanos, quando se trata do sistema interamericano, sendo resguardados os direitos e as liberdades das pessoas, independentemente da raça, cor, sexo, religião, idioma, opiniões, ou quaisquer outras circunstâncias (GOMES; SCHMIDT, 2014, p. 140).

O Brasil ratificou a Convenção Americana sobre Direitos Humanos, promulgando-a através do Decreto $\mathrm{n}^{\mathrm{o}}$ 678, de 06 de novembro de 1992, logo após a redemocratização brasileira, com a Constituição Federal de 1988, que, em seu artigo $5^{\circ}, \S 2^{\circ}$, dispôs que os direitos e garantias fundamentais previstos no documento constitucional não excluem outros decorrentes da comunidade internacional, previstos em Pactos que o Brasil seja parte (GOMES; SCHMIDT, 2014, p. 144).

Em razão da adesão do Brasil ao Pacto de San José da Costa Rica, como destaque, ainda que controverso ${ }^{5}$, sobre a sua aplicação, tem-se a proibição da prisão civil do depositário infiel, conforme a Súmula Vinculante $\mathrm{n}^{0} 25^{6}$ do Supremo Tribunal Federal, cuja formação adveio do reconhecimento da internalização, e assim da força cogente, dos direitos e garantias fundamentais previstos nos documentos internacionais ratificados pelo país.

\footnotetext{
5 Apesar de não ter revogado o dispositivo constitucional que autoriza a prisão do depositário infiel, à disposição do Pacto de San José da Costa Rica foi atribuída uma eficácia paralisante a fim de proibi-la (RE 466.343, rel. min. Cezar Peluso, voto do min. Gilmar Mendes, P, j. 3-12-2008, DJE 104 de 5-6-2009, Tema 60).

${ }^{6}$ É ilícita a prisão civil de depositário infiel, qualquer que seja a modalidade de depósito.
} 
De fato, a Constituição de 1988 aponta ser fundamento da República Federativa do Brasil a dignidade da pessoa humana, o que pode ser até visto como uma redundância, tendo em vista que, até o momento, não se reconhece outra pessoa que não seja a humana.

Análises semânticas a parte, segundo Ingo Sarlet (2012, p. 5455) o significado de dignidade humana constante da Constituição brasileira possui uma concepção comunitária, diante da igualdade de direitos e de dignidade de todos os cidadãos e de, nesse contexto, conviverem em uma comunidade.

O fato é que a Carta de 1988 foi a primeira da história constitucional do país a atribuir um título próprio aos princípios fundamentais, após o preâmbulo e antes dos direitos fundamentais. Com isso, o Poder Constituinte transpareceu seu intuito de atribuir a tais princípios o caráter de fundamentos da ordem constitucional, inclusive dos direitos e garantias fundamentais, sendo, portanto, seu núcleo essencial (SARLET, 2012, p. 98).

Contudo, a dignidade humana não restou restrita somente ao artigo $1^{\circ}$, mas a outros capítulos, como no artigo 170, caput, que trata da existência digna; no artigo $226, \S 7^{\circ}$, que trabalhou a paternidade responsável e o planejamento familiar nos moldes da dignidade; no artigo 227, caput, quando estabeleceu ser necessário assegurar à criança o direito à dignidade; bem como no artigo 225, caput, ao dispor sobre a dignidade intergeracional, com a imposição do dever de proteção do meio ambiente assegurando a sua qualidade para as presentes e futuras gerações.7 Verifica-se, portanto, que a ideia e a defesa da dignidade estão dissipadas em toda a Constituição, guiando a atuação dos atores políticos e sociais, e assim, o futuro brasileiro.

Apesar do grande desenvolvimento internacional em termos de direitos humanos, segundo Sarlet (2012, p. 102), nem todos os Estados

\footnotetext{
7 A dignidade nesse último caso comporta a construção das possibilidades de uma vida digna. E para se permitir exercitar tal direito é preciso perpassar por cinco deveres básicos: o reconhecimento do outro, o respeito, reciprocidade, responsabilidade e redistribuição, permitindo a todos não somente satisfazer as necessidades primárias, mas a desenvolver todas as suas faculdades secundárias, garantindo efetivamente dignidade humana (FLORES, Joaquín Herrera, 2009, p. 61-62).
} 
internalizaram em seus documentos jurídicos-políticos a previsão da dignidade humana como norte das disposições jurídicas internas, e isso provavelmente em razão de ainda pairar discussão sobre a universalidade dos direitos e garantias humanos, os quais, para os relativistas, são enxergados como um dado ocidental, de modo que a sua aplicação em outras culturas seria arbitrária (SARMENTO, 2016, p. 283-297).

\section{DIGNIDADE HUMANA: UM PRINCÍPIO ANTROPOCÊNTRICO}

Do desenvolvimento internacional da dignidade humana, observa-se que há um forte apego aos valores inerentes ao homem. Com efeito, o reconhecimento da dignidade como princípio internacional, capaz de fundamentar os demais direitos humanos, partiu da análise humanitária das consequências desastrosas das Grandes Guerras que dizimaram povos no século XX.

Foi nesse contexto, também, que a perspectiva ambiental ganhou força e se buscou garantir o meio ambiente ecologicamente equilibrado para garantir a proteção das presentes e das futuras gerações de seres humanos. Como expoente desse novo ideário se tem a Declaração de Estocolmo sobre o Meio Ambiente Humano (1972) que em seu artigo $1^{\circ}$ disciplina que:

1. O homem é ao mesmo tempo obra e construtor do meio ambiente que o cerca, o qual lhe dá sustento material e lhe oferece oportunidade para desenvolver-se intelectual, moral, social e espiritualmente. Em larga e tortuosa evolução da raça humana neste planeta chegou-se a uma etapa em que, graças à rápida aceleração da ciência e da tecnologia, o homem adquiriu o poder de transformar, de inúmeras maneiras e em uma escala sem precedentes, tudo que o cerca. Os dois aspectos do meio ambiente humano, o natural e o artificial, são essenciais para o bemestar do homem e para o gozo dos direitos humanos fundamentais, inclusive $\mathrm{o}$ direito à vida mesma (ORGANIZAÇÃO DAS NAÇÕES UNIDAS, 1972). 
Somente desse trecho da Declaração de 1972 é possível contar seis menções ao homem, como ator, produto e destinatário. A natureza e seus componentes são vistos como objetos, instrumentos e meios de conferir uma existência digna aos homens, o que é, inclusive, bem apontado no artigo $2^{\circ}$, que informa ser essencial ao bem-estar dos povos a proteção do meio ambiente, que é visto como "humano" (ORGANIZAÇÃO DAS NAÇÕES UNIDAS, 1972).

Tal viés é notadamente antropocêntrico, a primeira concepção que se tem sobre a ética ambiental, cujo critério para aferir quem faz parte ou não do âmbito de proteção ou é um sujeito a ser considerado pela comunidade moral é a razão, transmudada na capacidade de pensar e estabelecer conclusões lógicas (FELIPE, 2008, p. 1).

Com a superação da hegemonia de Deus sobre todas as coisas, a modernidade trouxe o homem para o centro das preocupações, em oposição a uma visão contemporânea de que a vida humana está inserida na natureza, sendo parte dessa e dos diversos ciclos ecológicos e biológicos existentes (BACKES, et. al., 2011, p. 264).

Todavia, segundo Nelson Choueri Júnior (2010, p. 109), a partir das investigações científicas, foi possível concluir que a origem da relação degradante entre o ser humano e a natureza advém da préhistória. Tal visão se sustentou durante séculos, até os dias atuais, tendo a modernidade não mais que fornecido os instrumentos necessários à propagação desse relacionamento abusivo.

Como o limite da corrente antropocêntrica é a razão, de modo que tudo o mais além disso tem um valor instrumental, a consideração dos demais seres e elementos naturais não passa de uma possibilidade ou necessidade, mas que pode, e deve, ser sublimada diante da importância da natureza humana para o equilíbrio ecológico e a manutenção da vida.

Tal perspectiva, ao revés do entendimento sobre a imprescindibilidade de se proteger o meio ambiente para o progresso humano, foi a responsável pela ampliação desenfreada de ações humanas degradantes sobre a natureza, de forma que tal corrente passou a ser vista como a responsável pelos maiores desastres 
ambientais ocorridos no mundo (CHOUERI JÚNIOR, 2010, p. 28 e 92).

Nota-se, inclusive, que a corrente antropocêntrica não se encontra somente nos estudos econômicos, tecnológicos ou de direitos fundamentais, mas no próprio direito ambiental 8 , disciplina desenvolvida com o foco nas preocupações sobre o futuro da espécie humana.

De fato, autores como Antunes (2010, p. 17-18) e Fiorillo (2013, p. 45-46) são enfáticos ao afirmarem que a proteção constitucional brasileira dada ao meio ambiente no artigo 225, é estritamente antropocêntrica, consagrando a dignidade humana, tendo em vista que os homens são os destinatários de todas as normas.

Bastante contraditório, mormente em razão da busca pela satisfação provisória, a proteção do meio ambiente teve seu fundamento na proteção do ser humano e na preservação da sua vida, sem que se que pretendesse internalizar ou trabalhar a ideia de que o homem faz parte da natureza9.

Por isso, o antropocentrismo, atualmente, vem sendo substituído, com mais ênfase em termos doutrinários, pela perspectiva biocêntrica, por uma ética que atribui relevância ao meio ambiente e a seus componentes por eles mesmos e em sua relação com o ser humano. Nesse viés, o homem cede espaço de destaque e passa a integrar uma relação de trocas com a natureza, de modo que se pretenda a preservação e a proteção daquela pela sua importância para além do gênero humano.

Pela ética biocêntrica, reconhece-se que a vida do ser tem valor, o qual não pode ser avaliado pelo critério da utilidade ou da finalidade. Desta feita, o elemento caracterizador da necessidade de

\footnotetext{
8 Segundo Talden Farias (2006, p. 126), o direito ambiental é ramo "da Ciência Jurídica capaz de regular as atividades humanas efetiva ou potencialmente causadoras de impacto sobre o meio ambiente, com o intuito de defendê-lo, melhorálo e de preservá-lo para as gerações presentes e futuras".

9 "Em outras palavras, advém o chamamento de que é impossível viver e sobreviver desconectados com a realidade cósmica e ecológica, energia e garantia da própria existência." (BACKES et. al., 2011, p. 267).
} 
proteção é a vida com qualidade de todos aqueles que podem ser afetados pela decisão do agente moral. De fato, a ética biocêntrica entende que há pelo menos dois interesses a serem considerados, quais sejam o do agente moral, ser racional, e o do paciente moral, não necessariamente dotado de racionalidade, mas capaz de sofrer danos pela conduta do agente moral (FELIPE, 2008, p. 3).

Os novos movimentos em prol da natureza, denominados ecológicos pretendem redefinir as relações entre o homem e o meio ambiente. A capacidade de conectar, relacionar e interrelacionar, destaca a impossibilidade de se separar os acontecimentos, as informações e os conhecimentos, uma vez que tudo está inserido num mesmo ciclo, num mesmo espaço, e o ser humano não está fora do ecossistema (BACKES et. al., 2011, p. 268).

O contexto socioambiental atual é inteiramente incompatível com a visão prevalecente desde a Idade Média de que o homem deve ser o centro de tudo. É preciso repensar as incertezas e as falhas dessa consideração e pretender olhar em volta, vez que há diversos seres no mundo, igualmente sencientes e importantes dentro do seu contexto. Toda espécie importa, basta ao homem reconhecer que a dignidade não é exclusivamente humana, mas abarca a vida.

\section{DIGNIDADE DA VIDA, DIGNIDADE DO SER}

De acordo com Vinicius Almada Mozetic e Aline Oliveira Mendes de Medeiros Franceschina (2014, p. 163), a dignidade é um conceito abrangente, de modo que é difícil conceituá-la especificamente, ainda mais por ser polissêmica. Ademais, no estágio atual da sociedade, desenvolve-se uma nova relação, homemnatureza, o que findou por alterar o Direito, e, assim, os limites da dignidade.

De fato, não é possível mais aceitar a tradicional definição de dignidade que orienta o tratamento especial dado aos animais humanos e, ao mesmo tempo, a conduta cruel direcionada aos animais 
não-humanos. O homem não é mais visto como um ser além e acima da natureza, mas pertencente a ela, componente do ecossistema e igualmente responsável pelo seu equilíbrio.

Assim, é preciso superar a noção de que a natureza deve ser protegida como condição para a manutenção do ambiente ecologicamente equilibrado para os homens, para entender que as medidas protetivas devem ser tomadas para a preservação da vida em si, atribuindo um valor intrínseco à vida, e não só particularmente ao homem.

Ingo Sarlet (2012, p. 37), neste sentido, afirma que esse novo comportamento, e, portanto, a admissão de uma dignidade para além da humana, não nega ou exclui a percepção de uma dignidade humana, que não é superior, tampouco excludente. Isso resulta em que a dignidade humana não é um conceito reduzido, mas abrangente, exigindo a proteção da vida.

Da mesma forma, Barroso (2012, p. 362) afirma que cresce a cada dia a percepção de que a posição especial conferida aos animais humanos não permite a desconsideração da natureza, incluindo os animais não-humanos, que possuem a sua própria dignidade. Então, os autores entendem ser possível falar em dignidade que não se centre na matriz humana. Sarlet (2012, p. 49) reconhece a dignidade humana com suas próprias características, que se centrou, ao longo da história, na doutrina kantiana, sendo o homem o centro e o fim, mas, ao mesmo tempo, retira o caráter imutável, não-dialogável do conceito, tendo em vista que entende tratar-se a dignidade de uma construção cultural.

E isso fica claro quando Sarlet e Fensterseifer (2007, p. 73) afirmam que a dignidade não é do indivíduo isolado, mas do grupo social a que pertence, de modo que para se concretizar o que se diz como dignidade é preciso refletir sobre o contexto e sobre a construção histórico-cultural.

Barroso (2012, p. 373), igualmente, aponta a existência de uma faceta comunitária na dignidade, a qual também pode ser representada pela restrição ou heteronomia. $\mathrm{O}$ valor social inerente à 
dignidade é o elemento limitante da autonomia privada, uma vez que o indivíduo pertencente a um grupo é restringindo pelos valores, costumes e normas formuladas em conjunto com seus pares.

Em razão do elemento social da dignidade humana e, consequentemente, da solidariedade, torna-se possível falar em uma dimensão ecológica da dignidade (BARROSO, 2010, p. 28), que não pode ser restringida à parte biológica ou física, mas trata da qualidade da vida como um todo (SARLET; FENSTERSEIFER, 2007, p. 73).

A dignidade como um valor que se inseriu nos ordenamentos estatais na forma de fundamento dos direitos tutelados, não pode ser limitada às concepções que excluem outras formas de vida igualmente relevantes. A ideia de que o homem está além da natureza já foi ultrapassada, vide os desastres ambientais atuais e os seus impactos na vida e saúde humana, e agora se busca reconhecer o espaço ocupado e como lidar com as novas relações emergentes ${ }^{10}$.

Portanto, a ideia embasada em Kant, de que a dignidade é atributo exclusivo do homem, é de um excessivo antropocentrismo, que não se sustenta diante da dignidade da vida, a qual merece ser preservada, ainda que se entenda ser uma condição para a proteção e para a sobrevivência humana (SARLET; FENSTERSEIFER, 2007, p. 76).

Diante do desenvolvimento de tal teoria, no julgamento da Ação Declaratória de Inconstitucionalidade n ${ }^{0}$ 4.983/CE, também conhecida como ADI da Vaquejada, o Ministro Luís Roberto Barroso afirmou, em seu voto, que as discussões no âmbito da ética têm evoluído no sentido da proteção dos animais, não como pressuposto ou condição para a proteção humana, ou garantia do meio ambiente ecologicamente equilibrado, mas como um valor autônomo (BRASIL, 2016).

Trabalhando as ideias, o Ministro afirma que o artigo 225, $\S 1^{\circ}$, VII da Constituição Federal não foi redigido apenas para assegurar o

${ }^{10}$ Vazamento de óleos na Bacia de Campos (2011); Rompimento da barragem de Mariana (2015); Rompimento da barragem de Brumadinho (2019), só para citar os mais recentes e de grande repercussão nacional. 
meio ambiente ecologicamente equilibrado, mas também para evitar a prática de crueldade contra animais, como as que ocorrem, por exemplo, nas farras do boi. Logo, a referida norma constitucional de proteção dos animais é autônoma, de forma que a proteção da integridade física e psicológica dos animais deve revestir-se de um caráter preservacionista, posto que os animais não são elementos inertes do ambiente (BRASIL, 2016).

A ética ambiental, neste contexto, promove papel primordial, tendo em vista que pretende estabelecer ligação entre os direitos humanos e a vertente ecológica, buscando a reestruturação do Direito num viés holístico.

Neste contexto, Martha Craven Nussbaum (2008, p. 117-119), ao tratar sobre a questão das competências e da justiça básica, apresenta alguns princípios políticos fundamentais, que podem ser aplicados aos animais não-humanos, como a vida - todos os animais têm direito a dar continuidade a sua vida, quer eles tenham consciência disso ou não; a integridade corporal - os animais possuem titularidade contra violações decorrentes de violência, abuso e outras formas de crueldade; emoções - os animais possuem emoções, como o medo e a alegria.

Destarte, o dever moral de tratamento adequado aos animais não tem fundamento na dignidade humana ou na compaixão, mas na própria dignidade da existência dos seres vivos, não se limitando exclusivamente aos animais não-humanos. Apesar disso, é possível pensar uma reformulação da própria dignidade humana que deve refletir os valores ecológicos que hoje permeiam a ideia de qualidade de vida (SARLET; FENSTERSEIFER, 2007, p. 82).

Nas palavras de Martha Nussbaum (2008, p. 126), para alcançar uma justiça verdadeiramente global é preciso não buscar outros animais humanos que possuam o direito a uma vida digna (pobres, minorias religiosas, minorias étnicas, etc.), mas sim olhar para o mundo a fim de perscrutar a existência de outros seres 
sensíveis, cujas vidas precisam igualmente ser preservadas e estão diretamente ligadas às vidas humanas.

Diante disso, a dignidade deve ser conceituada de forma subjetiva, ou seja, baseada no respeito. Algo possui dignidade quando é merecedor de respeito (FEIJÓ, 2008, p. 142). E, se isso é verdade, não há óbice a inserção dos animais não-humanos na comunidade moral. É preciso ir além da compartimentação da "modernidade sólida" e verificar a liquefação de institutos, das certezas, e começar a aceitar a criação de novos conceitos e valorações. Trata-se de um mundo novo.

\section{A DIMENSÃo ECOLÓGICA DA DIGNIDADE HUMANA: RESP. 1.797.175/SP e OPINIÃO CONSULTIVA No 23-2017}

Nesta vertente de ideias, de forma inédita, o Superior Tribunal de Justiça (STJ), em março de 2019, reconheceu, no Recurso Especial $\mathrm{n}^{0}$ 1.797.175/SP, a necessidade de se discutir a dimensão ecológica da dignidade humana no julgamento sobre domesticação de ave silvestre, especificamente do passeriforme popularmente conhecido como papagaio.

O caso trata de M. A. C. U., cidadã brasileira, que tinha em sua residência um papagaio, de nome Verdinho, há mais de vinte anos. Por se tratar de animal silvestre e a cidadã não possuir autorização para mantê-lo em cativeiro, ela acabou por ter imposta uma multa administrativa. Todavia, ela não só foi sancionada financeiramente com a possibilidade de pagamento da multa, como também o animal silvestre foi apreendido, sendo indicada a posterior inserção em seu habitat natural. Em sede recurso ao Tribunal de Justiça de São Paulo, o órgão julgador afastou a multa administrativa referente à manutenção ilegal de animal silvestre em cativeiro, por irregularidade no Auto de Infração Ambiental (AIA), mas manteve a multa quanto à constatação de maus-tratos. Todavia, deferiu a guarda provisória do animal à recorrente enquanto o Instituto Brasileiro do Meio Ambiente 
e dos Recursos Naturais Renováveis (IBAMA) não comprovasse a disponibilização de ambiente adequado ao papagaio.

A recorrente, não satisfeita, interpôs Recurso Especial ao STJ, obtendo parcial provimento nos termos do voto do Relator, Ministro Og Fernandes, que em sua fundamentação ressaltou a importância do reconhecimento da dimensão ecológica da dignidade humana, bem como da revisão da matriz kantiana que fundamenta a concepção geral vigente sobre aquele princípio. Neste sentido, o Relator assim argumenta:

Diante dessas inquietações, faz-se necessário, como já mencionado, repensar a concepção kantiniana individualista e antropocêntrica de dignidade e avançar rumo a uma compreensão ecológica da dignidade da pessoa e da vida em geral, considerando a premissão de que a matriz filosófica moderna para a concepção de dignidade (da pessoa humana) radica essencialmente no pensamento kantiniano (BRASIL, 2019, p. 9).

Ao final de suas razões, o Ministro pontua que a guarda deve ser mantida definitivamente em favor da recorrente, com algumas recomendações/exigências, em razão dos prejuízos morais, sociais e psicológicos que a separação poderia acarretar. Para tanto, ele enfatiza que a inserção do papagaio em outro ambiente, mesmo que considerado seu habitat natural, violaria a dimensão ecológica da dignidade humana, posto que as mudanças de ambiente causariam estresse no animal, levantando dúvidas sobre a viabilidade da readaptação.

Observa-se que, apesar de o Ministro não ter sido claro em afirmar os animais não-humanos como sujeitos de direito, ele deixou assente que a vida dos seres vivos é importante, independentemente de serem humanos ou não. O homem se insere na natureza, assim como os animais e, portanto, esses últimos devem ter a sua dignidade igualmente respeitada e considerada quando diante de situações em que são postos em risco, como o caso em comento.

O ordenamento jurídico brasileiro, apesar da matriz antropocêntrica que lhe é característica, está passando por transformações em razão da evolução perceptiva do homem sobre o 
mundo à sua volta. Recentemente, como já dito, no julgamento da ADI da Vaquejada, o Ministro Luís Roberto Barroso defendeu a autonomia do direito do animal não-humano não ser tratado com crueldade. Isso corrobora a tese de que a dignidade prevista nos ordenamentos jurídicos estatais e nos tratados internacionais não pode ser mais interpretada como exclusivamente humana.

É preciso captar a nuance da realidade moderna, das novas relações, e da necessidade de se mitigar o sentimento de superioridade que tornou o ser humano predador da própria espécie. Quantos desastres ambientais foram causados pelo sentimento especista, isto é, pela ideia de superioridade da espécie humana?

Essa tese cada vez mais ganha corpo no ambiente acadêmico, jurídico e político, nacional e internacional, de modo que também no âmbito do Sistema Interamericano de Direitos Humanos, a Corte Interamericana, criada pelo Pacto de San José da Costa Rica, emitiu a seguinte Opinião Consultiva (OC-23/17), em 15 de novembro de 2017, reconhecendo personalidade jurídica à Natureza:

62. Esta Corte considera importante destacar que o direito a um meio ambiente saudável como um direito autônomo, diferentemente de outros direitos, protege os componentes do meio ambiente, como florestas, rios, mares e outros, como interesses jurídicos em si mesmos, mesmo na ausência de certeza ou evidência de risco para os seres humanos. Trata-se de proteger a natureza e o meio ambiente, não apenas devido à sua conexão com uma utilidade humana ou aos efeitos que sua degradação poderia ter sobre outros direitos dos seres humanos, como a saúde, a vida ou a integridade pessoal, mas também por sua importância para os outros organismos vivos com os quais o planeta é compartilhado, também merecendo proteção por si mesmos ${ }^{99}$. Nesse sentido, a Corte observa uma tendência no reconhecimento da personalidade jurídica e, portanto, dos direitos, da natureza, não apenas nas decisões judiciais ${ }^{100}$, mas também nas ordens constitucionais ${ }^{101}$ (tradução nossa). ${ }^{11}$

11 62. Esta Corte considera importante resaltar que el derecho al medio ambiente sano como derecho autónomo, a diferencia de otros derechos, protege los componentes del medio ambiente, tales como bosques, ríos, mares y otros, como intereses jurídicos en sí mismos, aún en ausencia de certeza o evidencia sobre el riesgo a las personas individuales. Se trata de proteger la naturaleza y el medio ambiente no solamente por su conexidad con una utilidad para el ser humano o por los efectos que su degradación podría causar en otros derechos de las personas, como la salud, la vida o la integridad personal, sino por su importancia para los demás organismos vivos con quienes se comparte el planeta, también merecedores de 
$\mathrm{Na}$ Opinião Consultiva, ficou assente que a dignidade, o direito à vida e à integridade, não são só restritos aos seres humanos, mas também reconhecidos à natureza, ao meio ambiente, que deve ser protegido não só como condição para uma vida saudável para aqueles, mas em razão da importância da natureza em si.

Ressalta-se que as Opiniões Consultivas são instrumentos utilizados pela Corte Interamericana de Direitos Humanos para esclarecer o sentido e o alcance dos dispositivos da Convenção Americana de Direitos Humanos (ALMEIDA, 2019, n.p.). No caso em apreço, tratou-se da interpretação dos artigos 4.1 e 5.1 em relação aos artigos 1.1 e 2 da Convenção, nas vertentes meio ambiente e direitos humanos.

Com essa interpretação vários aspectos interpretativos transformaram-se, baseados, inclusive, nas Constituições LatinoAmericanos do início do século, tendo em vista que a Opinião Consultiva não é apenas opinativa e orientadora, mas, a partir da OC16/99, carrega consigo uma força vinculativa, de modo que acarreta responsabilidade internacional, além de ter papel incisivo no controle de convencionalidade (ALMEIDA, 2019, n.p.).

Assim, a referida Opinião Consultiva se mostra como uma evolução no pensamento antropocêntrico em vigor no Direito, para permitir a inclusão de outras formas de vida na comunidade moral. Esse novo olhar é produto das transformações sociais e das políticas dos países latino-americanos, expressas nas Constituições da Bolívia, do Equador, do Peru, que ressaltam a sutileza de se relacionar com a natureza e respeitá-la como ser vivo.

protección en sí mismos 99 . En este sentido, la Corte advierte una tendencia a reconocer personería jurídica y, por ende, derechos a la naturaleza no solo en sentencias judiciales ${ }^{100}$ sino incluso en ordenamientos constitucionales $^{101}$. (CORTE INTERAMERICANA DE DERECHOS HUMANOS, 2017, p. 29) (grifos nossos). 


\section{DIGNIDADE DA VIDA: TRANSFORMAÇÕES CONSTITUCIONAIS}

Como dito no item anterior, o desenvolvimento da ideia de uma dimensão ecológica da dignidade humana é corroborado pela inserção, nos ordenamentos jurídicos estatais, do respeito à natureza, e de seus componentes, como sujeitos de direitos e, assim, igualmente importantes.

De fato, a Constituição do Equador de 2008 é enfática ao dispor que a natureza possui direitos, dentre eles o respeito a sua existência e manutenção, in verbis:

Art. 71. A natureza ou Pacha Mama, onde a vida se reproduz e se realiza, tem direito ao pleno respeito da sua existência e a manutenção e regeneração de seus ciclos vitais, estrutura, funções e processos evolutivos.

Art. 72. A natureza tem direito à restauração. Essa restauração será independente da obrigação que o Estado e as pessoas naturais ou jurídicas têm de indenizar os indivíduos e comunidades que dependam do ecossistema afetado (tradução nossa). ${ }^{12}$

Pacha Mama, segundo Zelma Tomaz Toletino e Liziane Paixão Silva Oliveira (2015, p. 315), é um mito andino que se refere ao tempo vinculado a terra. O tempo é curador dos males, o que extingue as alegrias, aquele que estabelece as estações e fecunda a terra. A terra é um ser vivo, é a Pachamama dos índios, a Gaia a que se referem os cosmólogos contemporâneos.

Assim, a natureza (Pacha Mama) é o planeta, a vida, a qual deve ser protegida, independentemente de ser exclusivamente humana. Os seus processos, suas relações, sua evolução, devem ser resguardados e respeitados, não pelo homem, mas por seu valor intrínseco. Nas palavras dos autores:

\footnotetext{
12 Art. 71.La naturaleza o Pacha Mama, donde se reproduce y realiza la vida, tiene derecho a que se respete integralmente su existencia y el mantenimiento y regeneración de sus ciclos vitales, estructura, funciones y procesos evolutivos.

Art. 72.La naturaleza tiene derecho a la restauración. Esta restauración será independiente de la obligación que tienen el Estado y las personas naturales o jurídicas de indemnizar a los individuos y colectivos que dependan de los sistemas naturales afectados (REPÚBLICA DO EQUADOR., 2008, p. 52).
} 
O certo é que a natureza, juntamente com o ser humano, constitui uma realidade indivisível. Diante de tal constatação, é necessária a proteção da vida humana e da natureza, mas é igualmente essencial a tutela do meio ambiente em si mesmo considerado, visto que a degradação ambiental é nociva ao ser humano e, também, afeta a vida da natureza e do meio ambiente (TOLETINO; OLIVEIRA, 2015, p. 324).

A Constituição da Bolívia, por sua vez, traz em seu artigo 33 que:

As pessoas têm o direito ao meio ambiente saudável, protegido e equilibrado. O exercício desse direito deve permitir que os indivíduos e comunidades das presentes e futuras gerações, além de outros seres vivos, se desenvolvam de forma normal e permanente (tradução nossa). ${ }^{13}$

Nessa disposição, o povo boliviano se expressa no sentido de que o direito ao meio ambiente equilibrado é de todos, inclusive dos seres não-humanos, como pressuposto para seu desenvolvimento pessoal normal e contínuo.

Apesar do grande enfoque dado pelos países latinoamericanos nos últimos tempos à proteção da natureza, no continente europeu, a Suíça, na Constituição de 1999 dispõe expressamente sobre a dignidade da criatura em seu artigo 120:
A Confederação prescreve disposições sobre a manipulação com material embrionário e genético de animais, plantas e outros organismos. Para isto, leva em conta a dignidade da criatura, assim como a segurança do homem, dos animais e do meio-ambiente e protege a variedade genética das espécies de animais e vegetais (tradução nossa). ${ }^{14}$

\section{A Suíça é considerada o primeiro país a proteger} constitucionalmente os animais. Desde 1893, a Constituição Suíça já

\footnotetext{
13 Las personas tienen derecho a un medio ambiente saludable, protegido y equilibrado. El ejercicio de este derecho debe permitir a los individuos y colectividades de las presentes y futuras generaciones, además de otros seres vivos, desarrollarse de manera normal y permanente (ESTADO PLURINACIONAL DA BOLÍVIA, 2009, p. 10-11).

${ }^{14}$ Der Bund erlässt Vorschriften über den Umgang mit Keim- und Erbgut von Tieren, Pflanzen und anderen Organismen. Er trägt dabei der Würde der Kreatur sowie der Sicherheit von Mensch, Tier und Umwelt Rechnung und schützt die genetische Vielfalt der Tier- und Pflanzenarten (CONFEDERAÇÃO SUÍÇA,2020).
} 
protegia os animais do abate sem anestésico. Atualmente, com a disposição do artigo 120, o povo suíço conferiu um novo olhar aos animais, atribuindo-lhes valor inerente, o qual deve ser observado ainda no âmbito da engenharia genética (FREITAS, 2012, p. 330).

A inclusão do artigo 20a ${ }^{15}$ na Lei Fundamental da Alemanha também se apresenta como um marco na evolução da percepção da dignidade e superação do antropocentrismo, uma vez que traz em seu âmago a proteção dos recursos naturais e dos animais (FREITAS, 2012, p. 331).

Tais enunciados prescritivos revelam-se como reflexos das mudanças sociais e culturais ocorridas A fundamentação kantiana de que o ser humano não pode ser tratado como meio, e que aos animais somente são devidos deveres indiretos, está sendo aos poucos superada. A natureza é um ser vivo que merece dignidade. O homem é apenas um componente dela, e por isso não é seu criador, é criatura, e como criatura deve reconhecer a existência dos demais.

Como apontado por Michael Kloepfer (2005, p. 60-61, apud SARLET; FENSTERSEIFER, 2019, p. 1), a reinvindicação de direitos para a natureza e para os animais não é estranha por ser contrária à ordem constitucional contemporânea, mas porque vai de encontro à tradição religiosa-cultural de que o ser humano molda o mundo. Todavia, tal concepção é mutável, como ocorreu com os direitos das mulheres, dos escravos e dos indígenas.

De fato, até pouco tempo atrás, as mulheres eram tolhidas em diversos direitos, como o voto e a capacidade civil; os negros eram escravos pela cor da sua pele, e, portanto, eram coisas, podendo ser vendidos e tratados da forma como bem aprouvesse o seu dono. Agora,

15 Artikel 20a Der Staat schützt auch in Verantwortung für die künftigen Generationen die natürlichen Lebensgrundlagen und die Tiere im Rahmen der verfassungsmäßigen Ordnung durch die Gesetzgebung und nach Maßgabe von Gesetz und Recht durch die vollziehende Gewalt und die Rechtsprechung (REPÚBLICA FEDERAL DA ALEMANHA, 2020). Artigo 20a Tendo em conta também a sua responsabilidade frente às gerações futuras, o Estado protege os recursos naturais vitais e os animais, dentro do âmbito da ordem constitucional, através da legislação e de acordo com a lei e o direito, por meio dos poderes executivo e judiciário (tradução nossa). 
é a vez da natureza, dos animais, dos seres vivos, somente é preciso superar o especismo segregador e se colocar no mundo ao lado daqueles que também o compõe. A natureza clama por direitos.

\section{CONSIDERAÇÕES FINAIS}

A sociedade, assim como o sistema jurídico, nacional e internacional, está passando por um processo de reflexão sobre a forma de pertencimento ao mundo. Os seres humanos, antes ensimesmados, agora abrem os olhos para o ambiente à sua volta $\mathrm{e}$ conferem importância aos ciclos do qual fazem parte.

Assim como ocorreu no epicentro Iluminista, com a substituição de Deus como centro das atenções e como protagonista das ações, o ser humano, nessa fase de transição, cede espaço para os seres vivos. Não é possível mais perpetuar a proposição kantiana de o ser humano como centro de tudo e os animais como meros objetos destinatários de possíveis desvelos de amor e cuidado.

A natureza clama por espaço e por reconhecimento, e a dignidade, longe de ser um conceito estanque, reverbera todas as matizes sociais, econômicas, políticas e culturais da comunidade em que é positivada e interpretada. Logo, a dignidade não pode ser um atributo exclusivamente humano, sem se reconhecer o valor inerente a outras formas de vida.

Nesse passo, a dimensão ecológica da dignidade humana torna-se uma interpretação plausível, não só para o direito nacional, como também para o direito internacional, conforme se observou no julgamento do REsp 1.797.175/SP e na Opinião Consultiva no 23-2017, os quais foram além da percepção simplista, centrada exclusivamente no eu humano, para vislumbrar o horizonte de perspectivas que a evolução social comporta.

O homem aprende, agora, a conviver com novas formas de compatibilizar o seu desenvolvimento com a manutenção dos demais 
seres vivos. Não é possível mais pensar em uma proteção da natureza e dos animais não-humanos como meios para o fim humano, porquanto a natureza tem seu ciclo, sua importância, e, dessa forma, a necessidade de proteção compatível com suas particularidades.

Essa mudança de paradigma é algo que ainda se encontra em construção, apesar de a natureza há muito clamar por respeito e proteção como um fim em si mesmo, haja vista as atrocidades cometidas pelos seres humanos pela perspectiva do antropocentrismo segregador, que foca exclusivamente no desenvolvimento da espécie humana a todo custo.

Todavia, mesmo ainda em desenvolvimento, é possível verificar situações específicas, despontamentos sociais e jurídicos, que demonstram o passo à frente dado pela humanidade, vide as mudanças operadas em alguns ordenamentos jurídicos europeus, havendo a diferenciação entre os animais e as coisas para fins de tratamento normativo.

Além desses casos, há os dos países latino-americanos, mormente a Bolívia e Equador, que atribuíram direitos à natureza, os quais são, inclusive, afirmados em sede jurisdicional, em respeito à tradição popular, e a relação íntima e particular que os povos indígenas possuem com o meio ambiente natural.

Esse novo olhar jurídico sobre os animais e sobre a natureza é reflexo da evolução do conceito de dignidade, que não deixa de ter o aspecto/análise humano, mas apresenta um olhar sobre os seres vivos como um todo, de acordo com as suas particularidades e a necessidade de serem inseridos na comunidade moral.

Diante disso, a leitura constitucional e internacional da dignidade humana deve acompanhar as novas percepções, as quais despontam com o desenvolvimento do estudo do meio ambiente e de seus componentes, sem descurar da possibilidade de que os seres vivos possam titularizar direitos perante os homens.

Data de Submissão: 04/12/2019 
Dignidade Da Natureza: Uma Ressignificação Da Dignidade Humana

Data de Aprovação: 16/03/2020

Processo de Avaliação: double blind peer review

Editor Geral: Jailton Macena de Araújo

Editor de Área: Fernando Joaquim Ferreira Maia

Assistente Editorial: Maria Joaquina Cavalcanti

\section{REFERÊNCIAS}

ALMEIDA, Raquel Santos de. Opinião Consultiva OC-23/17 Meio Ambiente e Direitos Humanos. Não paginado. In: Núcleo Interamericano de Direitos Humanos. Rio de Janeiro: Faculdade Nacional de Direito da UFRJ, 2019. Disponível em: https://nidh.com.br/oc23. Acesso em: 20 out. 2019.

ANTUNES, Paulo de Bessa. Direito Ambiental. 12. ed. Rio de Janeiro: Lumen Juris, 2010.

AVANCINI, Helenara Braga. A dignidade da pessoa humana e a incorporação do direito internacional dos direitos do homem no direito interno luso-brasileiro. Revista de Propriedade Intelectual - Direito Contemporâneo e Constituição, Aracaju, ano II, ed. 4/2013, p.76-98, out. 2013.

BACKES, Marli Terezinha Stein et. al. Do antropocentrismo ao ecologicentrismo: formação para o cuidado ecológico na saúde. Revista Gaúcha de Enfermagem, Porto Alegre, v. 32, n. 2, p. 263-269, jun. 2011.

BARROSO, Luís Roberto. A Dignidade da Pessoa Humana no Direito Constitucional Contemporâneo: Natureza Jurídica, Conteúdos Mínimos e Critérios de Aplicação. Versão provisória para debate público. Mimeografado, dezembro de 2010.Disponível em:

http://luisrobertobarroso.com.br/wpcontent/uploads/2016/o6/Dignidade_texto-base_11dez2010.pdf. Acesso em: 01 set. 2019.

BARROSO, Luís Roberto. Here, There, and Everywhere: Human Dignity in Contemporary Law and in the Transnational Discourse. Boston College International and Comparative Law Review, Boston, v. 35, n.2, p. 331-393, jan. 2012.

BRASIL. Supremo Tribunal Federal (Plenário). Ação Direta de Inconstitucionalidade $n^{0}$ 4.983. Processo Objetivo - Ação Direta de Inconstitucionalidade - Atuação do Advogado-Geral da União. Vaquejada - Manifestação Cultural - Animais - Crueldade Manifesta - Preservação da Fauna e da Flora - Inconstitucionalidade. Requerente: Procurador-Geral da República. Interessados: 
Assembleia Legislativa do Estado do Ceará e Governador do Estado do Ceará. Relator: Ministro Marco Aurélio, o6 de outubro de 2016. Disponível em:

http://portal.stf.jus.br/processos/downloadPeca.asp?id=311683661 \&ext=.pdf. Acesso em: 15 out. 2019.

BRASIL. Superior Tribunal de Justiça (2. Turma). Recurso Especial $\mathrm{n}^{0}$ 1.797.175 - SP (2018/0031230-0). Administrativo. Ambiental. Recurso Especial. Não configurada a violação do art. 1.022 do CPC. Inexistência de omissão, obscuridade ou contradição. Multa judicial por embargos protelatórios. Inaplicável. Incidência da Súmula 98 do STJ. Multa Administrativa. Rediscussão de matéria fática. Impossibilidade. Súmula 7 do STJ. Invasão do mérito administrativo. Guarda provisória de animal silvestre. Violação da dimensão ecológica do princípio da dignidade humana. Recorrente: Maria Angélica Caldas Uliana. Recorrida: Fazenda do Estado de São Paulo. Relator: Ministro Og Fernandes, 21 de março de 2019. Disponível em:

https://ww2.stj.jus.br/processo/revista/documento/mediado/?comp onente $=$ ATC\&sequencial $=92773702 \&$ num_registro $=201800312300$ $\&$ data $=20190513 \&$ tipo $=51 \&$ formato $=$ PDF. Acesso em 21 out. 2019.

CANOTILHO, José Joaquim Gomes. Direito Constitucional e Teoria da Constituição. 7. ed. Coimbra: Almedina, 2003.

CARVALHO, Regina Ribeiro Parizi; MARTINS, Gerson Zafalon; GRECO, Dirceu Bartolomeu. Sociedade Brasileira de Bioética: uma bioética de compromissos. Revista Bioética, Brasília, v. 25, n. 2, p. 218-223, ago. 2017. Disponível em: http://www.scielo.br/scielo.php?script=sci_arttext\&pid=S198380422017000200218\&lng=en\&nrm=iso. Accesso em 15 mar. 2020.

\section{CHOUERI JÚNIOR, Nelson. Investigações em torno do} antropocentrismo e da atual crise ecológica. 2010. $123 \mathrm{f}$. Dissertação (Mestrado em Metafísica) - Curso de Filosofia, Departamento de Filosofia, Universidade Federal do Rio Grande do Norte, Natal, 2010.

\section{CONFEDERAÇÃO SUÍÇA. [Constituição 1999]. Constituição}

Federal da Confederação Suíça. Berna: Assembleia Federal. 2020. Disponível em: https://www.admin.ch/opc/de/classifiedcompilation/19995395/index.html. Acesso em: 12 mar. 2020.

CORTE INTERAMERICANA DE DERECHOS HUMANOS. Opinión Consultiva OC-23/17, de 15 de novembro de 2017. Obligaciones estatales en relación con el medio ambiente en el marco de la protección y garantía de los derechos a la vida y a la integridad personal - interpretación y alcance de los artículos 4.1 y 5.1, en relación con los artículos 1.1 y 2 de la convención americana sobre 
derechos humanos. San José: Corte Interamericana de Derechos Humanos, 2017. Disponível em:

<https://www.refworld.org.es/docid/5ade36fe4.html>. Acesso em: O5 out. 2019.

ESTADO PLURINACIONAL DA BOLÍVIA. Constituição 2009. Constitución Política del Estado. Sucre: Presidência da República, 2009. Disponível em: <https://www.oas.org/dil/esp/Constitucion_Bolivia.pdf>. Acesso em: 23 out. 2019.

FARIAS, Talden. Princípios gerais do direito ambiental. Prim@ Facie, Paraíba, v. 5, n. 9, p. 126-148, jul./dez. 2006.

FEIJÓ, Anamaria Gonçalves dos Santos. A dignidade e o animal nãohumano. In: MOLINARO, Carlos Alberto et al (org.). A dignidade da vida e os direitos fundamentais para além dos humanos: uma discussão necessária. Belo Horizonte: Fórum, 2008. p. 128-143.

FELIPE, Sônia. Ética biocêntrica: tentativa de superação do antropocentrismo e sencientismo éticos. Ethic@ - An

International Journal For Moral Philosophy, Florianópolis, v. 7, n. 3, p.1-7, dez. 2008.

FIORILlO, Celso Antônio Pacheco. Curso de Direito Ambiental brasileiro. 14. ed. rev., ampl. e atual. em face da Rio+20 e do novo "Código" Florestal São Paulo: Saraiva, 2013.

FREITAS, Renata Duarte de Oliveira. Proteção jurídico constitucional do animal não-humano. Revista Brasileira de Direito Animal, Salvador, v. 7, n. 10, p.325-344, jan./jun. 2012.

GOMES, Eduardo Biacchi; SCHMIDT, Ayeza. O princípio da dignidade da pessoa humana: un diálogo entre fontes e o HC 91.952 (SP). In: Anais do XXIII Encontro Nacional do Conpedi. Florianópolis: CONPEDI, 2014. p. 131 - 148.

GUERRA, Sidney. Os direitos humanos na ordem jurídica internacional. Pensar - Revista de Ciências Jurídicas, Fortaleza, v. 14, n. 1, p.188-203, jun. 2009.

FLORES, Joaquín Herrera. A (re)invenção dos direitos humanos. GARCIA, Carlos Roberto Diogo; SUXBERGER, Antônio Henrique Graciano; DIAS, Jefferson Aparecido (tradutores). Florianópolis: Fundação Boiteux, 2009.

KANT, Immanuel. A metafísica dos costumes. Tradução, texto adicionais e notas: Edson Bini. Bauru: EDIPRO, 2003. 
KANT, Immanuel. Fundamentação da Metafísica dos

Costumes. Traduzida do alemão por Paulo Quintela. Portugal:

Edições 70 LDA, 2007.

MENDES, Gilmar Ferreira. A dignidade da pessoa humana na Constituição Federal de 1988 e sua aplicação pelo Supremo Tribunal Federal. Observatório da Jurisdição Constitucional, Brasília, ano 6, n. 2, p.83-97, jul./dez. 2013.

MOZETIC, Vinicius Almada; FRANCESCHINA, Aline Oliveira Mendes de Medeiros. A dimensão fundamental ecológica da dignidade da pessoa humana. Revista de Direito Econômico e Socioambiental, Curitiba, v. 5, n. 1, p.161-179, jan./jun. 2014.

NOVAIS, Jorge Reis. A dignidade da pessoa humana. Dignidade e Direitos Fundamentais. v.1. Coimbra: Almedina, 2015. ISBN 978972-40-6157-3.

NUSSBAUM, Martha Craven. Para além de "compaixão e humanidade": Justiça para animais não-humanos. In: MOLINARO, Carlos Alberto et al (org.). A dignidade da vida e os direitos fundamentais para além dos humanos: uma discussão necessária. Belo Horizonte: Fórum, 2008. p. 86-126.

ORGANIZAÇÃO DAS NAÇÕES UNIDAS. Declaração de Estocolmo sobre o Ambiente Humano, de 16 de junho de 1972. Estocolmo: Organização das Nações Unidas, 1972. Disponível em: <http://www.direitoshumanos.usp.br/index.php/MeioAmbiente/declaracao-de-estocolmo-sobre-o-ambientehumano.html>. Acesso em: 23 out. 2019.

REPÚBLICA DO EQUADOR. Constituição 2008. Constitución de La Republica del Ecuardor. Quito: Presidência da República, 2008. Disponível em: <https://www.derechoecuador.com/Files/images/Documentos/Con stitucion-2008.pdf>. Acesso em: 05 out. 2019.

REPÚBLICA FEDERAL DA ALEMANHA. Constituição 1949. Lei Fundamental da República Federal da Alemanha. Berlim: Parlamento Federal Alemão, 2020. Disponível em: https://www.bundestag.de/parlament/aufgaben/rechtsgrundlagen/g rundgesetz/gg_02-245124. Acesso em: 12 mar. 2020.

SARLET, Ingo Wolfgang. Dignidade da pessoa humana e direitos fundamentais na Constituição Federal de 1988. 9. ed. rev. atual. 2. tir. Porto Alegre: Livraria do Advogado Editora, 2012.

SARLET, Ingo Wolfgang; FENSTERSEIFER, Tiago. Algumas notas sobre a dimensão ecológica da dignidade da pessoa humana e sobre a 
Dignidade Da Natureza: Uma Ressignificação Da Dignidade Humana

dignidade da vida em geral. Revista Brasileira de Direito

Animal, Salvador, ano 2, n. 3, p.69-94, jul./dez. 2007.

SARLET, Ingo Wolfgang; FENSTERSEIFER, Tiago. Do direito constitucional ambiental ao direito constitucional ecológico. Consultor Jurídico, São Paulo, ago. 2019. Disponível em: https://www.conjur.com.br/2019-ago-30/direito-constitucionalambiental-direito-constitucional-ecologico. Acesso em: 23 out. 2019.

SARMENTO, Daniel. Dignidade da pessoa humana: Conteúdo, Trajetórias e Metodologia. Belo Horizonte: Fórum, 2016.

SWINARSKI, Christophe. O DIREITO INTERNACIONAL HUMANITÁRIO COMO SISTEMA DE PROTEÇÃO INTERNACIONAL DA PESSOA HUMANA. Revista do Instituto Brasileiro de Direitos Humanos, Fortaleza, n. 4, p. 33-48, dez. 2003 .

TOLENTINO, Zelma Tomaz; OLIVEIRA, Liziane Paixão S.. Pachamama e o Direito à Vida: Uma Reflexão na Perspectiva do Novo Constitucionalismo Latino Americano. Veredas do Direito: Direito Ambiental e Desenvolvimento Sustentável, Belo Horizonte, v. 12, n. 23, p.313-335, out. 2015.

VITA, Jonathan Barros. Valoração aduaneira e preços de transferência: pontos de conexão e distinções sistêmicoaplicativas. pontos de conexão e distinções sistêmico-aplicativas. 2010. Tese (Doutorado em Direito Tributário), Pontificia Universidade Católica de São Paulo, São Paulo, 2010. 


\title{
Dignity Of Nature: A Resignification Of Human Dignity
}

\author{
Ingrid de Lima Barbosa
}

\author{
José Orlando Ribeiro Rosário
}

\begin{abstract}
Today, the era of animal consciousness is proclaimed, that is, the overcoming of the speciesist and anthropocentric paradigm that places human beings above all species. Such a change of perspective begins with the resignification of human dignity to beyond human animals, giving it an ecological aspect. It is intended, therefore, to analyze the possibility of a linguistic opening of human dignity to the ecological bias of today and, thus, to advocate for the dignity of life, which goes beyond the human species. The dialectical method was used for the objective of presenting a new conception of reality, allied to the theoretical analytical and documental approach, of qualitative nature, along with the critical analysis of the interpretations attributed to the principle of human dignity, as well as the change of reality which today presents itself to scholars, with the utmost concern given to the environment as an end in itself. This scientific method was realized through the use of books, scientific articles, academic papers (Dissertations), a higher court decision and international documents. It was concluded that the constitutional and international reading of human dignity must accompany the new perceptions that emerge with the development of the study of environment and its components, without neglecting the possibility that nonhuman animals may hold rights before men.
\end{abstract}

Keywords: Animals. Human dignity. Sentience.

DOI: https://doi.org/10.22478/ufpb.1678-2593.2021v20n44.49520

Conteúdo sob licença Creative Commons: Attribuition-NonCommercial-NoDerivative 4.o International (CC BY-NC-ND 4.0)

(cc) BY-NC-ND 